\title{
Structural Changes of Zoospores During and After Net Formation in Hydrodictyon reticulatum
}

\author{
Kyoko Hatano and Keizo Maruyama \\ Department of Natural Environment Sciences, Faculty of Integrated Human Studies, \\ Kyoto University, Kyoto 606-8501, JAPAN \\ Tel 81-75-753-6854; Fax 81-75-753-6864
}

Received January 16, 1999

\begin{abstract}
Changes in the cell structure during and after net formation of zoospores in Hydrodictyon reticulatum were investigated by electron and fluorescence microscopy. Many small vesicles were accumulated around zoospores, and these vesicles later restricted the movement of zoospores. Immediately after cessation of the movement of polyhedral zoospores, the plasma membrane evaginated to form thread-like projections around the closely approaching regions of adjacent zoospores. Then the projections seemed to fuse with the adjacent zoospores. Once the connections between the adjacent cells were formed by the projections, the contact between two zoospores became progressively tighter. Cell wall materials were deposited on the plasma membrane about 10 minutes after cessation of the cell movement. Cell wall materials appeared firstly as electron-dense discontinuous patches on the plasma membrane. The patches then expanded to connect with one another, finally forming a single electron-dense cell wall layer which covered the cell surface. Netcells were finally linked by their cell walls. Cell wall substances continued to be accumulated in the space between the electron-dense cell wall layer and the plasma membrane.
\end{abstract}

Key words. cell adhesion, cell wall formation, Hydrodictyon reticulatum, net formation, zoospores.

\section{Introduction}

During the asexual reproductive cycle of Hydrodictyon reticulatum, the cytoplasm of the mature vegetative cell is divided to form hundreds of zoospores, which later adhere to one another to form a beautiful hexagonal network. The dynamic changes in the forms of cells seen during and after net formation of zoospores provoke many fundamental questions about the morphogenesis of cells: how do moving zoospores gradually change their shape? How do adjacent zoospores adhere to each other? How are the cell walls formed around the plasma membranes of naked cells?

A number of botanists have observed the detailed process of net formation of zoospores in $H$. reticulatum by light, electron and fluorescence microscopy (Pocock, 1960; Hawkins and Leedale, 1971; Marchant and Pickett-Heaps, 1972a; Hatano and Ueda, 1988; Hatano, 1991; Hatano and Maruyama, 1995), but the structural changes in the surfaces of the cells during and after net formation have not yet been determined in detail. It is expected that our understanding of the 
mechanism of morphogenesis in $H$. reticulatum will be advanced by morphological studies. This investigation deals with the ultrastructure of the cells from young zoospores to net-cells. Special attention is paid to the surfaces of cells which will adhere to each other to form the hexagonal network and to cells which will form cell walls on their plasma membranes.

\section{Materials and Methods}

Hydrodictyon reticulatum was isolated from a pond in Nara, Japan. Cells were cultured in Waris medium (Waris, 1950) at $23^{\circ} \mathrm{C}$ under fluorescent light with a photon flux density of $46 \mu \mathrm{mol}$ $\mathrm{m}^{-2} \mathrm{~s}^{-1}$ for $14 \mathrm{~h}$ per day. The formation of zoospores was induced by the transfer of mature vegetative cells into fresh culture medium at the beginning of the light period. The zoospores were formed early in the next light period.

For transmission electron microscopy, cells were fixed for $4 \mathrm{~h}$ at $4^{\circ} \mathrm{C}$ with $5 \%$ glutaraldehyde buffered with phosphate at $\mathrm{pH}$ 7.4. Cells were washed with phosphate buffer, post-fixed overnight at $4^{\circ} \mathrm{C}$ with $1 \%$ osmium tetroxide buffered at $\mathrm{pH} 7.4$, washed for $1 \mathrm{~h}$ with water, dehydrated with acetone and embedded in Spurr resin (Spurr, 1969). Ultrathin sections were stained with lead citrate and examined with a Hitachi $\mathrm{H}-7000$ electron microscope.

For scanning electron microscopy, cells were frozen in liquid propane at $-190^{\circ} \mathrm{C}$ and then transferred to chilled acetone containing $2 \%$ osmium tetroxide at $-85^{\circ} \mathrm{C}$. After $48 \mathrm{~h}$ at $-85^{\circ} \mathrm{C}$, they were gradually warmed to room temperature, washed with acetone, treated with iso-amyl acetate for $5 \mathrm{~h}$ at $4^{\circ} \mathrm{C}$, and dried with an apparatus for critical-point drying. Cells fixed on a specimen holder were coated with gold and examined with a Hitachi S-430 scanning electron microscope.

For observation of cell wall formation, cells that had ceased movement for 10 or 40 minutes were stained with $0.2 \%$ Calcofluor White M2R (Polysciences, Inc, Warrington, PA, USA) in Waris medium for 5 minutes. Cells were washed with Waris medium and examined under an Olympus fluorescence microscope with an ultraviolet excitation filter. Photographs were taken on Kodak TMAX400 film.

\section{Results}

Spherical zoospores with two flagella moved actively in the narrow space between the central vacuole and the plasma membrane of the parental vegetative cells. In electron micrographs, they did not appear as smooth spheres due to distortion during the preparation procedures. Many spherical and ovoid vesicles were seen around the zoospores without cell walls (Fig. 1). Vesiculation of the plasma membrane was seen frequently, which suggests that the vesicles might have been formed from the surface of the zoospores (Fig. 1, arrow; Fig. 2, arrowhead). At the beginning of the zoospore movement, these vesicles were few in number, but they increased as the zoospores came into contact with adjacent zoospores.

The nucleus was located in the anterior part of the moving zoospores (Fig. 2). Dictyosomes, about $1 \mu \mathrm{m}$ in diameter, were seen close to the nucleus. The outer nuclear envelope formed small vesicles by budding and pinching off near the proximal faces of the dictyosomes (Fig. 2, arrows). Many vesicles were observed between the nuclear envelope and the proximal faces of the dictyosomes, which may be originated from the nuclear envelope. During and after net formation of zoospores, the dictyosomes kept their position near the nucleus. Endoplasmic reticulum (ER) with ribosomes was observed throughout the cytoplasm.

Moving zoospores gradually changed their shape from spherical to polyhedral. Vesicles were also seen between the adjacent surfaces of apposed polyhedral zoospores (Fig. 3, v). It is not clear 

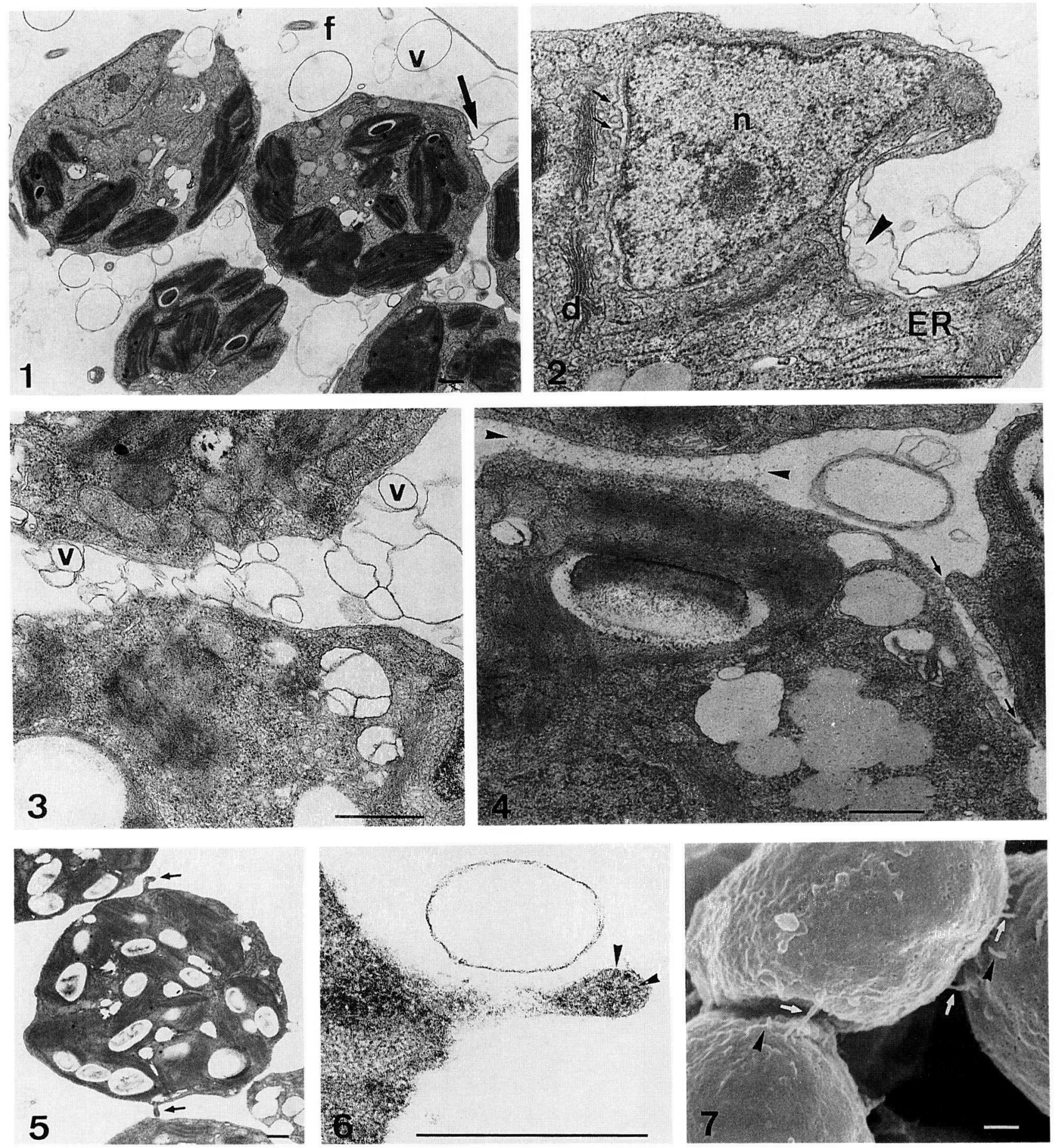

Fig. 1. Spherical zoospores. Vesicles (v) are seen around zoospores. Some parts of the plasma membranes of the zoospores are evaginated (arrow). f: flagellum. Fig. 2. The anterior part of a moving zoospore, showing the nucleus (n), dictyosomes (d), endoplasmic reticulum (ER) and protrusions of the outer nuclear envelope (arrows). Vesicles seem to be formed actively at the cavity near the nucleus (arrowhead). Fig. 3. Vesicles (v) in the space between two approaching zoospores. Fig. 4. Three cells after cessation of movement. Fibrous substances (arrowheads) between two cells are visible. Two cells are partially in contact with each other as shown by the arrows. Fig. 5. A cell with thread-like projections (arrowheads). Fig. 6. Fibrous structure (arrowheads) in a projection. Fig. 7. Scanning electron micrograph of the cells soon after they stopped moving. Projections (arrowheads) and bridges (arrows) are visible. Figs. 1-7. Bars $=0.5 \mu \mathrm{m}$. 

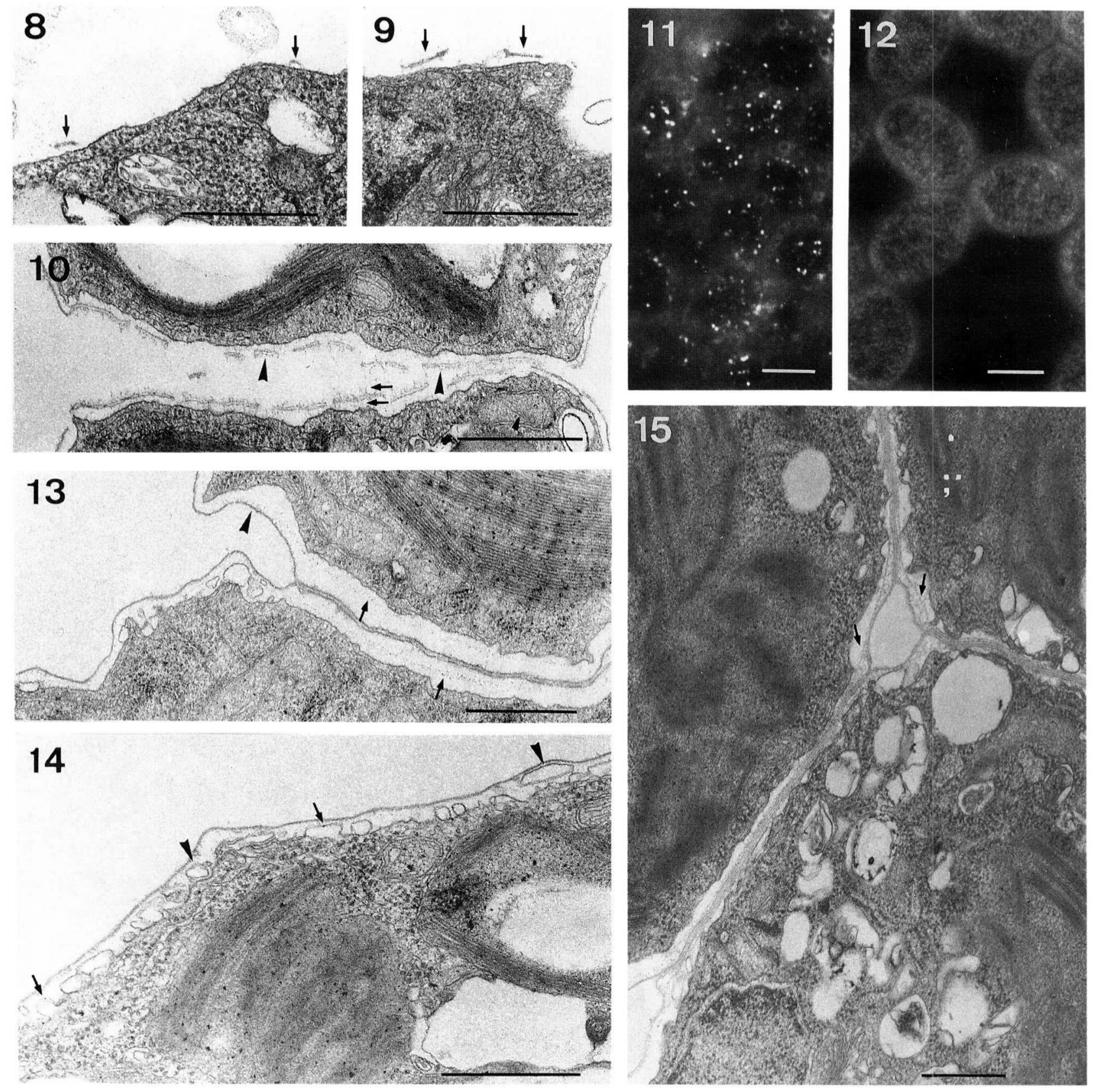

Fig. 8. Part of a cell at the beginning of cell wall formation. Small patches (arrows) of cell wall materials are seen adjacent to the plasma membrane but separated from it by a short distance. Fig. 9. Part of a cell at an early stage of cell wall formation. Patches (arrows) are larger in diameter than those at previous stages. Fig. 10. Transverse section of the contacting region of two adjacent cells. Patches (arrowheads) have already grown extensively. Fluffy substances (arrows) are visible on the surface of the patches. Fig. 11-12. Fluorescence images of the cell walls of net-cells stained with Calcofluor White M2R. Fig. 11. Cells 10 minutes after the cessation of movement. Fig. 12. Cells 40 minutes after the cessation of movement. Fig. 13. Transverse section of the adhering region of two cells. Patches have completely fused to form a thin sheet with high electron density (arrowhead). Fig. 14. Vesicles (arrowheads) between the cell wall and the plasma membrane. Arrows show the protrusions of the plasma membrane. Fig. 15. Transverse section of the adhering region of three cells. Electron-dense substances (arrows) have been accumulated between the cell wall and the plasma membrane. Figs. 8-10. Bars=0.5 $\mu \mathrm{m}$. Figs. 11-12. Bars=5 $\mu \mathrm{m}$. Figs. 13-15. Bars $=0.5 \mu \mathrm{m}$. 
whether these vesicles were of the same type with the same functions as those seen around spherical zoospores at previous stages. Polyhedral zoospores retracted their flagella into the cytoplasm soon after they stopped moving, as was reported by Marchant and Pickett-Heaps (1972a). The cell wall was not yet detected on the cell surface by electron microscopy at this stage. Fibrous substances were seen between the closely apposed surfaces of two cells (Fig. 4, arrowheads). These fibrous substances might have originated from the vesicles previously located at the same position. Fig. 4 (arrows) shows the partial fusion of plasma membranes of two adjacent cells.

Thread-like projections of the cytoplasm were formed near the approaching regions of adjacent cells (Fig. 5). They were about $0.1 \mu \mathrm{m}$ in diameter. These projections occurred at the peripheries of the apposed regions and extended from one cell to another. These projections seemed to fuse with neighboring cells to connect two adjacent cells, although no direct evidence for such fusion was obtained. Fine fibrils or fine tubules were seen in the projections (Fig. 6). Intercellular cytoplasmic bridges were also observed by scanning electron microscopy at the peripheries of the approaching regions of adjacent polyhedral cells (Fig. 7, arrows).

Cells originating from polyhedral zoospores became spherical about 5 minutes after they stopped moving. Cytoplasmic projections or bridges between two cells were not seen on the surfaces of spherical cells, probably due to a rapid decrease in the length of these structures after bridging. Small electron-dense patches of cell wall materials appeared on the cell surface about 10 minutes after cessation of the cell movement (Fig. 8, arrows). The appearance of these patches was the first sign of cell wall formation. At a later stage, the patches expanded in length (Fig. 9, arrows) and increased in number and diameter (Fig. 10). Both surfaces of the patches were covered with fluffy substances (Fig. 10, arrows). During the expansion, the patches fused and formed a reticulum when neighboring patches came in contact with each other (Fig. 10). The area of patches continued to expand until the holes in the reticulum was closed. Cell wall formation in newly adhered net-cells was monitored with Calcofluor White M2R. When net-cells were only briefly stained and then transferred to a dye-free medium, faint patches were visible on the surfaces of the net-cells 10 minutes after the cessation of movement (Fig. 11). There were many small, randomly distributed patches of brighter fluorescence on the surfaces of the cells at 40 minutes after the cessation of movement (Fig. 12). The photomicrographs were printed to show the patterns of cell wall fluorescence and do not accurately reflect differences in fluorescence intensity.

Fig. 13 shows a part of two cells which are in contact with each other through newly formed cell walls. The electron-dense cell wall layer (Fig. 13, arrowhead) was widely separated from the plasma membranes. Between the plasma membrane and the cell wall layer, there were fibrous substances which may have been the remnant of the fluffy substances covering the surfaces of patches (Fig. 13, arrows). Soon thereafter, the plasma membrane produced many small vesicles by means of evagination and pinching off (Fig. 14). Similar vesicles were not seen outside of the cell wall. These vesicles differed in appearance and size from the vesicles around zoospores. These vesicles might have contributed to the thickening of the adjacent cell wall. The space between the cell wall and the plasma membrane became electron dense after the vesicle production from the plasma membrane stopped (Fig. 15).

\section{Discussion}

Before the net formation, the speed of movement of the zoospores decreased, which should have enhanced the ability of the zoospores to contact and adhere to each other. If zoospores were moving actively, connection and adhesion between them would probably be very difficult. Many vesicles were seen around zoospores. These vesicles seemed to be released continuously from the 
plasma membranes of zoospores. Light microscopic observation showed that mucous substances or vesicles around zoospores were in contact with the tonoplast, and that zoospores could move only within the mass of mucous substances (Data not shown here). Mucous substances which appeared as vesicles in electron micrographs thus reduced the free space within which zoospores could move. As the mucous substances increased, the movement of zoospores became slower. Thus, continuous release of vesicles from zoospores should result in the decrease of the zoospore movement.

Thread-like projections of cytoplasm appeared around the closely approaching regions of adjacent polyhedral cells soon after retraction of flagella and cessation of the movement of zoospores. These projections may attach to neighboring zoospores, and close contact between two zoospores may take place subsequently. The possibility that the vesicles excreted outside the zoospores act as an adhesive substance cannot be excluded, but the presence of the thread-like projections seems to be much more powerful morphological evidence about the initial connection between two zoospores. Stopping the movement of zoospores by retracting the flagella enables the thin projections to connect the large zoospores without breakage. Once the bridging projections are formed, the distance between two zoospores soon becomes progressively shorter.

Connection between two cells through projections occurs during fertilization or conjugation in algae. For instance, the structure of the fertilization tube in the gametes of Chlamydomonas reinhardi is known in detail: the fertilization tube extends from mating-type-plus gametes to mating-type-minus gametes, and cell fusion subsequently occurs (Friedmann et al., 1968). In this case, a fertilization tube consisting of thread-like projections acts to catch another cell and to fuse with it. In the case of Hydrodictyon reticulatum, small projections are used not only for fertilization (Marchant and PickettHeaps, 1972b) but also for the linkages between somatic cells. It is interesting that the two kinds of motile cells, the zoospores and the gametes, produce similar thread-like structures to perform two different processes, fertilization and net formation.

For the elongation of the fertilization tube, the polymerization of actin filaments has been proposed in C. reinhardi (Goodenough and Weiss, 1975; Detmers and Goodenough, 1980). In $H$. reticulatum, tubular and filamentous structures were observed in the thread-like projections, suggesting that the polymerization of actin and/or tubulin takes place during the elongation of projections.

A unique process of cell wall formation was observed in $H$. reticulatum: the cell wall was not detected on the surface of zoospores, but it appeared as discontinuous patches, and developed to form a continuous sheet on the cell surface after the retraction of flagella. Cell wall formation on the plasma membranes of naked cells has been observed in detail in some kinds of algae with electron microscopy; for instance, the cell wall formation following fertilization of the eggs of Pelvetia fastigiata (Peng and Jaffe, 1976) and cell wall regeneration on the plasma membranes of protoplasts of Boergesenia forbesii (Itoh et al., 1984) and Skimmia japonica (Robenek and Peveling, 1977). In these cases, cell walls are deposited with uniform thickness on the plasma membrane. In Pediastrum boryanum and $P$. simplex, Scenedesmus pannonicus and $S$. longus, which belong to the same order as $H$. reticulatum, the cell wall appears first as discontinuous plaques on the plasma membrane (Millington and Gawlik, 1970, 1975; Pickett-Heaps and Staehelin, 1975). In contrast to $H$. reticulatum, the plaques of Pediastrum are deposited at specific sites, namely at the corners of the hexagons in the reticulate pattern in the wall. The sites of the plaques have been thought to correspond to clusters of ribosomes on the endoplasmic reticulum underlying the plasma membrane (Gawlik and Millington, 1969; Millington and Gawlik, 1970, 1975). In H. reticulatum, the surface of the cell wall of vegetative cells is not ornamental. The bright patches of fluorescence on the new cell wall exhibited no orderly distribution detectable by fluorescence microscopy. Cells of Pediastrum, Scenedesmes and Hydrodictyon start cell wall formation or patch-formation, after adhesion of adjacent cells after the changes in the cell shape begin; in $P$. boryanum and $P$. simplex, 
from spheres to flat cylinders with one or two horns, in $S$. pannonicus and $S$. longus, from ellipsoids to spheres, and in $H$. reticulatum, from spheres to cylinders. Initiation of cell wall formation by production of discontinuous patches may be suitable for cell wall formation accompanied by changes in the cell shape and rapid increases in the cell volume. Therefore, it may be characteristic of Chlorococcales algae, which form asexually reproducing colonies.

The discontinuous patches are similar in appearance to scales in other algae (Moestrup and Walne, 1979; Mcfadden et al., 1986). Scales are one of the important characteristics for taxonomy; previously, Prasinophyceae was classified as belonging to Chlorophyceae, but was separated later from Chlorophyceae primarily because it had scales. However, there is a great difference between patches and scales. The former develop in size and fuse with one another to form a continuous layer, while the latter remain unchanged in size after they take specific positions in or outside the cell. Whether the patches and the scales are homologous structures in the evolution of plants is a problem to be addressed in the future.

After the completion of the cell wall layer by the fusion of patches, many small vesicles are observed between the cell wall layer and the plasma membrane in $H$. reticulatum. Vesicles are formed by protrusion of the plasma membrane followed by pinching off from the plasma membrane. Some substances necessary for the cell wall development are assumed to be transported to the cell wall in these vesicles. Cell wall formation in green alga has been well investigated in the cells of Micrasterias. In Micrasterias, flat vesicles produced by dictyosomes are incorporated into the plasma membrane during the secondary wall formation (Kiermayer and Dobberstein, 1973; Ueda and Noguchi, 1976). Rosette complexes, which are observed in the plasma membrane and in the membrane of the flat vesicles, have been assumed to play an important role in microfibril formation in the cell wall (Giddings et al. 1980; Noguchi et al. 1981). In H. reticulatum, the mechanism by which the vesicles that are produced by the plasma membrane contribute to the cell wall formation has not yet been determined.

\section{Acknowledgement}

We are grateful to Honorary Professor K. Ueda, Nara Women's University for valuable discussions.

\section{References}

Detmers, P. A. and Goodenough, U. W. 1980. Actin in the Chlamydomonas mating type + mating structure. J. Cell Biol. 87: 220a (Abstr.).

Friedmann, I., Colwin, A. L. and Colwin, L. H. 1968. Fine-structural aspects of fertilization in Chlamydomonas reinhardi. J. Cell Sci. 3: 115-128.

Gawlik, S. R. and Millington, W. F. 1969. Pattern formation and the fine structure of the developing cell wall in colonies of Pediastrum boryanum. Amer. J. Bot. 56: 1084-1093.

Giddings, T. H. Jr., Brower, D. L. and Staehelin, L. A. 1980. Visualization of particle complexes in the plasma membrane of Micrasterias denticulata associated with the formation of cellulose fibrils in primary and secondary cell walls. J. Cell Biol. 84: 327-339.

Goodenough, U. W. and Weiss, R. L. 1975. Gametic differentiation in Chlamydomonas reinhardii. III. Cell wall lysis and microfilament-associated mating structure activation in wild-type and mutant strains. J. Cell Biol. 67: 623-637.

Hatano, K and Ueda, K. 1988. Changes in the shape of mitochondria during asexual reproductive cycle in Hydrodictyon reticulatum. Eur. J. Cell Biol. 47: 193-197. 
Hatano, K. 1991. Changes in microtubule arrangement during the asexual reproductive cycle in Hydrodictyon reticulatum. J. Phycol. 27 (3 suppl.): 29.

Hatano, K. and Maruyama, K. 1995. Growth pattern of isolated zoospores in Hydrodictyon reticulatum (Chlorococcales, Chlorophyceae). Phycol. Res. 43: 105-110.

Hawkins, A. F. and Leedale, G. F. 1971. Zoospore structure and colony formation in Pediastrum spp. and Hydrodictyon reticulatum (L.) Langerheim. Ann. Bot. 35: 201-211.

Itoh, T., O'Neil, R. M. and Brown, R. M. Jr. 1984. Interference of cell wall regeneration of Boergesenia forbesii protoplasts by Tinopal LPW, a fluorescent brightening agent. Protoplasma 123: 174-183.

Kiermayer, O. and Dobberstein, B. 1973. Membrankomplexe dictyosomaler Herkunft als "Matrizen" fur die extraplasmatische Synthese und Orientierung von Mikrofibrillen. Protoplasma 77: 437451.

Marchant, H. J. and Pickett-Heaps, J. D. 1972a. Ultrastructure and differentiation of Hydrodictyon reticulatum. III. Formation of the vegetative daughter net. Aust. J. Biol. Sci. 25: 265-278.

Marchant, H. J. and Pickett-Heaps, J. D. 1972b. Ultrastructure and differentiation of Hydrodictyon reticulatum. IV. Conjugation of gametes and the development of zygospores and azygospores. Aust. J. Biol. Sci. 25: 279-91.

Mcfadden, G. I., Preisig. H. R. and Melkonian, M. 1986. Golgi apparatus activity and membrane flow during scale biogenesis in the green flagellate Scherffelia dubia (Prasinophyceae). II: Cell wall secretion and assembly. Protoplasma 131: 174-184.

Millington, W. F. and Gawlik, S. R. 1970. Ultrastructure and initiation of wall pattern in Pediastrum bolyanum. Amer. J. Bot. 57: 552-561.

Millington, W. F. and Gawlik, S. R. 1975. Cell shape and wall pattern in relation to cytoplasmic organization in Pediastrum simplex. Amer. J. Bot. 62: 824-832.

Moestrup, O. and Walne, P. L. 1979. Studies on scale morphogenesis in the Golgi apparatus of Pyramimonas tetrarhunchus (Prasinophyceae). J. Cell Sci. 36: 437-459.

Noguchi, T., Tanaka, K. and Ueda, K. 1981. Membrane structure of dictyosomes, large vesicles and plasma membranes in a green alga, Micrasterias crux-melitensis. Cell. Struct. Funct. 6: 217-229.

Peng, H. B. and Jaffe, L. F. 1976. Cell-wall formation in Pelvetia embryos. A freeze-fracture study. Planta 133: 57-71.

Pickett-Heaps, J. D. 1975. Green Algae. Structure, reproduction and evolution in selected genera. Sinauer Associates, Inc., Publ. Sunderland, Massachusetts.

Pickett-Heaps, J. D. and Staehelin, L. A. 1975. The ultrastructure of Scenedesmus (Chlorophyceae). II. Cell division and colony formation. J. Phycol. 11: 186-202.

Pocock, M. A. 1960. Hydrodictyon: A comparative biological study. Jl. S. Afr. Bot., 26: 167-319.

Robenek, H. and Peveling, E. 1977. Ultrastructure of the cell wall regeneration of isolated protoplasts of Skimmia japonica Thunb. Planta 136: 135-145.

Spurr, A. R. 1969. A low-viscosity epoxy resin embedding medium for electron microscopy. J. Ultrastruct. Res. 26: 31-49.

Ueda, K. and Noguchi, T. 1976. Transformation of the Golgi apparatus in the cell cycle of a green alga, Micrasterias americana. Protoplasma 87: 145-162.

Waris, H. 1950. Cytophysiological studies on Micrasterias. I. Nuclear and cell division. Physiol. Pl. 3: $1-16$. 